\title{
Shifts of rumen microbial population detected by real-time PCR when methanogenesis is inhibited*
}

\author{
Y.Q. Guo ${ }^{1}$ J. X. Liu ${ }^{1,4}$, W.Y. Zhu' ${ }^{2}$ and C. McSweeney ${ }^{3}$ \\ ${ }^{1}$ Institute of Dairy Science, Ministry of Education Key Laboratory of Molecular Animal Nutrition \\ Zhejiang University, Hangzhou 310029, P.R. China \\ ${ }^{2}$ Gastrointestinal Microbiology Laboratory, Nanjing Agricultural University \\ Nanjing 210095, P.R. China \\ ${ }^{3}$ CSIRO Livestock Industries
}

306 Carmody Rd. St Lucia, QLD, 0467, Australia

\begin{abstract}
Real-time PCR was conducted to quantify methanogens, bacteria, Fibrobacter succinogenes, Ruminococcus flavefaciens and fungi in rumen fluid incubated in vitro when methane synthesis was inhibited. After $24 \mathrm{~h}$ incubation, methanogens in sodium salt of 2-bromoethanesulphonic acid (BES)-added fluids was reduced to $10.4 \%$ of control $(\mathrm{P}<0.01)$. BES did not significantly influence the number of bacteria and $R$. flavefaciens. However, the number of $F$. succinogenes in BES-treated fluid was $50.0 \%$ higher than in control $(\mathrm{P}<0.01)$. Population density of fungi fell by $61.9 \%(\mathrm{P}<0.01)$ in comparison with control. Addition with BES changed the rumen microbiota and had a varying influence on different microbes.
\end{abstract}

KEY WORDS: in vitro, bromoethanesulphonic acid, molecular technology, methanogenesis

\section{INTRODUCTION}

The global cattle population is responsible for $73 \%$ of methane emissions of all livestock, and methane produced during ruminal fermentation represents a loss of $2-15 \%$ of gross energy intake and may contribute to global warming (Johnson and Johnson, 1995).

The symbiotic rumen ecosystem consists of mostly obligate anaerobic microorganisms including fungi, protozoa, bacteria and archaea. Ruminal

\footnotetext{
* Supported partly by National Natural Science Foundation of China, Grant No.30530560 and Coordinated Research Projects from Joint FAO/IAEA Division, IAEA, No. 12665/R0

${ }^{4}$ Corresponding author: e-mail: liujx@zju.edu.cn
} 
microbiologists have long sought to develop strategies for reducing ruminal methanogenesis within the rumen ecosystem, including defaunation (Hu et al., 2005), feed formulation, adding electron acceptors and stimulation of acetogens.

However, most methane inhibiting strategies occurred different in vivo and in vitro, and the underlying influence on microbial flora is unclear as well. The development of real-time PCR technology has greatly facilitated the realization of nucleic acid quantification (Tajima et al., 2001). It is currently feasible to analyse the change of different species in the rumen.

The present study was conducted to detect the change of rumen microflora based on real-time PCR approach when methnogenesis was inhibited. Bromoethanesulphonic acid, a known inhibitor of methnaogenesis, was selected as agent.

\section{MATERIAL AND METHODS}

\section{In vitro fermentation}

In vitro fermentation was conducted using Reading Pressure Technique system (Mauricio et al., 1999). Incubation was performed in $180 \mathrm{ml}$ serum vials in quadruples for $24 \mathrm{~h}$, with or without $5 \mathrm{mM}$ 2-bromoethanesulphonic acid, sodium salt (BES) (Sigma-Aldrich, Germany). Rumen fluids were collected before morning feeding from two fistulated sheep fed a mixed ration ( $60 \%$ lucerne hay plus $40 \%$ concentrate mixture) at 1.3 maintenance levels. Ten $\mathrm{ml}$ of strained rumen inoculum was added into each flask and mixed with $90 \mathrm{ml}$ pre-injected buffer medium.

After incubation for 4, 8, 12 and $24 \mathrm{~h}$, accumulated head-space gas pressure was recorded. One hundred $\mu 1$ of gas sample was removed to detect methane concentration using gas chromatograph (GC2010, Shimadzu, Japan) equipped with a flame ionization detector capillary column (HP-INNOWAX, 19091N133). The temperatures of the injector/detector and the column were 130 and $80^{\circ} \mathrm{C}$, respectively. The sum of methane emission at different time points was considered as total amount of methane production. Volatile fatty acids (VFA) were determined by gas chromatography. Hydrogen balance was calculated from the amounts of acetate (A), propionate (P), butyrate (B) and methane (M) formed in fermentation according to the stoichiometric model proposed by Demeyer and Van Nevel (1975). A 1-ml portion of the rumen fluid was sampled at 0, 12 and 24 $\mathrm{h}$ incubation, respectively, and stored at $-80^{\circ} \mathrm{C}$ for DNA extraction.

\section{Total DNA extraction and PCR procedure}

Total DNA from rumen fluid was extracted through freezing/thawing method for cell lysis firstly, purified by guanidine thiocyanate, and then bound to a glass matrix. 
Primer pairs for rumen fungi, F. succinogenes, $R$. flavefaciens and total rumen bacteria were described by Denman and McSweeney (2006). The sequences of primers for methanogens were as follows: TTCGGTGGATCDCARAGRGC (forward) and GBARGTCGWAWCCG TAGAATCC (reverse) (Denman and McSweeney, personal communication).

Real time qPCR was performed using Bio-Rad iCycler iQ Multicolor real-time PCR detection system (Bio-Rad Laboratories, Inc.) with fluorescence detection of SYBR Green dye. Amplification condition was as follows: one cycle at $95^{\circ} \mathrm{C}$ for $3 \mathrm{~min}$ for initial denaturation and then 40 cycles of $95^{\circ} \mathrm{C}$ for $30 \mathrm{~s}$ followed by annealing and extending at $60^{\circ} \mathrm{C}$ for $1 \mathrm{~min}$. Detection of the fluorescent product was set at the last step of each cycle.

Relative quantification was used to quantify methanogens, fungi, F. succinogenes and $R$. flavefaciens, which were expressed as proportions of total rumen bacteria. Total bacteria at different time points were showed for reference. The numbers of bacteria at 12 and $24 \mathrm{~h}$ were expressed as relative number of bacteria at $0 \mathrm{~h}$, which was taken as $1.00(100 \%)$.

\section{Statistical analysis}

Statistical analysis of data was performed by analysis of variance (ANOVA) differences determined by the method of least significant differences at the $1 \%$ level $(\mathrm{P}<0.01)$. All statistical analysis was run with SAS 8.0 (SAS Inst. Inc., Cary, NC).

\section{RESULTS}

The effects of BES on gas production and methane release in vitro are shown in Figure 1. After $24 \mathrm{~h}$ incubation, BES significantly depressed $(\mathrm{P}<0.01)$ gas production and inhibited methane emission by $85.7 \%(\mathrm{P}<0.01)$.

Total VFAs and molar proportions of acetate, propionate and butyrate were significantly affected by BES (Table 1). The molar proportion of acetate and the ratio of acetate-to-propionate were reduced $(\mathrm{P}<0.01)$ while the proportions of propionate and butyrate were increased $(\mathrm{P}<0.01)$, indicating that $\mathrm{BES}$ altered the fermentation pattern.

The hydrogen balance (Table 1) reflected variations in daily methane release. BES reduced $(\mathrm{P}<0.01)$ hydrogen production, utilization and recovery after $24 \mathrm{~h}$ incubation. 


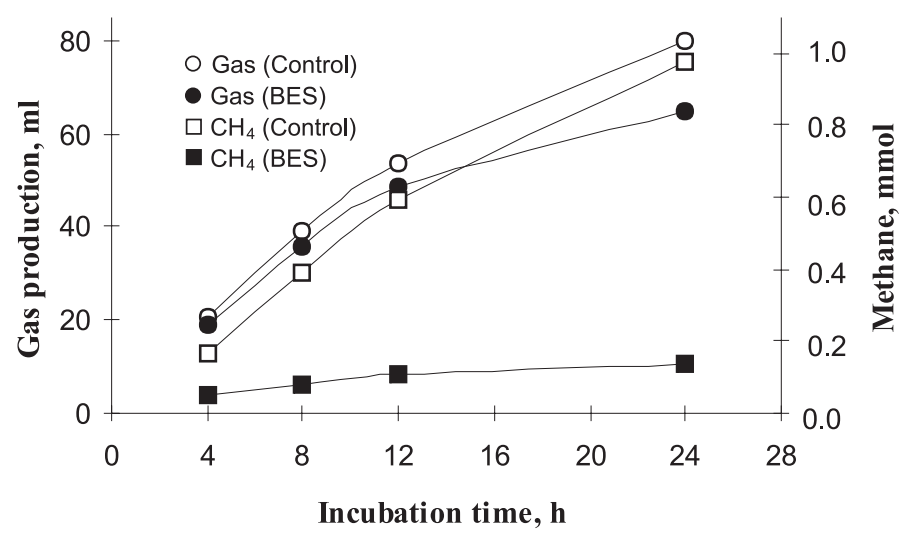

Figure 1. In vitro gas production ( $\circ$ and $\bullet$ ) and methane emission ( $\square$ and $\boldsymbol{\square}$ ) of rumen fluids

Table 1. Effects of BES on rumen fermentation and microorganism

\begin{tabular}{|c|c|c|c|c|c|c|c|}
\hline \multirow{2}{*}{$\begin{array}{l}\text { Incubation time, } \mathrm{h} \\
\mathrm{BES}\end{array}$} & \multirow[t]{2}{*}{0} & \multicolumn{3}{|c|}{12} & \multicolumn{3}{|c|}{24} \\
\hline & & - & + & SEM & - & + & SEM \\
\hline \multicolumn{8}{|l|}{ Volatile fatty acids } \\
\hline total,mmol/1 & 9.9 & $28.8^{\mathrm{A}}$ & $26.5^{\mathrm{B}}$ & 0.34 & $36.6^{\mathrm{A}}$ & $31.3^{\mathrm{B}}$ & 0.27 \\
\hline \multicolumn{8}{|l|}{ Molar proportions, $\%$} \\
\hline acetate & 74.4 & $69.4^{\mathrm{A}}$ & $64.7^{\mathrm{B}}$ & 0.34 & $69.1^{\mathrm{A}}$ & $63.4^{\mathrm{B}}$ & 0.26 \\
\hline propionate & 11.2 & $19.5^{\mathrm{B}}$ & $22.3^{\mathrm{A}}$ & 0.19 & $19.6^{\mathrm{B}}$ & $23.7^{\mathrm{A}}$ & 0.25 \\
\hline butyrate & 14.4 & $11.1^{\mathrm{B}}$ & $13.0^{\mathrm{A}}$ & 0.18 & $11.3^{\mathrm{B}}$ & $13.0^{\mathrm{A}}$ & 0.26 \\
\hline acetate/propionate & 6.66 & $3.56^{\mathrm{A}}$ & $2.90^{\mathrm{B}}$ & 0.045 & $3.52^{\mathrm{A}}$ & $2.68^{\mathrm{B}}$ & 0.046 \\
\hline \multicolumn{8}{|l|}{ Hydrogen balance } \\
\hline produced,mmol/d & ND & ND & ND & ND & $7.4^{\mathrm{A}}$ & $6.3^{\mathrm{B}}$ & 0.07 \\
\hline utilized,mmol/d & ND & ND & ND & ND & $6.2^{\mathrm{A}}$ & $2.9^{\mathrm{B}}$ & 0.05 \\
\hline recovery, $\%$ & ND & ND & ND & ND & $83.78^{\mathrm{A}}$ & $46.03^{\mathrm{B}}$ & 0.005 \\
\hline \multicolumn{8}{|l|}{ Microbes } \\
\hline totalbacteria & 1.00 & 2.29 & 2.44 & 0.128 & 3.75 & 3.77 & 0.167 \\
\hline \multicolumn{8}{|c|}{ Proportion of total bacteria,\% } \\
\hline methanogens & 0.042 & 0.015 & 0.013 & 0.0008 & $0.106^{\mathrm{A}}$ & $0.011^{\mathrm{B}}$ & 0.0052 \\
\hline F.succinogenes & 0.043 & 0.030 & 0.029 & 0.0013 & $0.022^{\mathrm{B}}$ & $0.033^{\mathrm{A}}$ & 0.0009 \\
\hline R.flavefaciens & 0.012 & $0.005^{\mathrm{A}}$ & $0.003^{\mathrm{B}}$ & 0.0001 & 0.002 & 0.002 & 0.0001 \\
\hline fungi & 0.128 & $0.015^{\mathrm{A}}$ & $0.009^{\mathrm{B}}$ & 0.0007 & $0.063^{\mathrm{A}}$ & $0.024^{\mathrm{B}}$ & 0.0040 \\
\hline
\end{tabular}

${ }_{\mathrm{A}, \mathrm{B}}$ different capital letters within rows indicate treatment differences $(\mathrm{P}<0.01 ; \mathrm{n}=3)$

ND - not determined

Total bacteria was increased after $24 \mathrm{~h}$ incubation, however, it was not affected by BES ( $\mathrm{P}>0.05$; Table 1$)$. Methanogens at $12 \mathrm{~h}$ incubation was lower than that 
before incubation, but there was no significant difference between control and BES-treated rumen fluid. After $24 \mathrm{~h}$ incubation, a marked decrease in methanogens was observed in the presence of BES $(\mathrm{P}<0.01)$. F. succinogenes was increased by $50 \%$ after $24 \mathrm{~h}$ incubation $(\mathrm{P}<0.01)$. On the contrary, another fibrolytic bacterium, $R$. flavefaciens, fell by $40 \%$ at $12 \mathrm{~h}$ of incubation in comparison with control, and a further decreased were observed in both fluids with or without BES, but no significant difference was observed. A dramatic reduction in fungi was observed when methanogenesis was inhibited. Population density of fungi was declined by 40.0 and $61.9 \%$, compared with control after incubation for 12 and $24 \mathrm{~h}$, respectively.

\section{DISCUSSION}

Methane production from rumen inoculum was decreased with the addition of BES. In the rumen, about $82 \%$ of the methane formed comes from reduction of $\mathrm{CO}_{2}$ by hydrogen, while about $18 \%$ is derived from formate. Coenzyme $\mathrm{M}(\mathrm{CoM}$; $\mathrm{HSCH}_{2} \mathrm{CH}_{2} \mathrm{SO}_{3}^{-}$) is a cofactor involved in the terminal step of methane biosynthesis, where the methyl group carried by $\mathrm{CoM}$ is reduced to methane by methyl-CoM reductase, while CoM is present only in methanogens. The $\mathrm{BES}\left(\mathrm{BrCH}_{2} \mathrm{CH}_{2} \mathrm{SO}_{3}^{-}\right)$ is a structural analogue of $\mathrm{CoM}$ and a potent inhibitor of methanogenesis. Because this terminal step is involved in all methane biosynthesis, BES has been used and regarded as a methanogen-specific inhibitor in microbiological studies and does not appear to inhibit the growth of other bacteria (Sparling and Daniels, 1987). In the present study, BES inhibited methane synthesis and obstructed the growth of methanogens. The result is in agreement with the finding of Sparling and Daniels (1987). Due to the differences in cell envelope structure among methanogens, different response of methanogens to BES may occur. However, these changes were not showed through this experiment. Further investigation is required to clarify the influence of BES on specific order of methanogens.

Although hydrogen is one of the major end products of fermentation by all species of anaerobic fungi and some pure monoculture of bacteria, such as $R$. flavefaciens, it does not always accumulate in the rumen because it is immediately used by other bacteria that are present in the mixed microbial ecosystem. When hydrogen is not correctly used by methanogens, for instance, when hydrogen accumulates, hydrogen production from $\mathrm{NADH}_{2}$ is not thermodynamically feasible and saccharolytic organisms will synthesize larger amounts of reduced products (i.e. propionate). In the present study, molar proportion of propionate increased in BES-treated fluid. The cellulolytic bacteria, F. succinogenes, is the major propionate producer through the succinate pathway in roughage diets (Moss et al., 2000). The elevated F. succinogenes was revealed by real time PCR 
in our study. Lower recovery of hydrogen was found in the BES-added fluid. It is accordance with the finding of Sauer and Teatcher (1987) that a higher hydrogen pressure occurred in rumen inoculum supplemented with BES. With the increased hydrogen pressure, rumen fermentation patterns were changed. One of the explanations for the reduced numbers of $R$. flavefaciens and fungi may be that the microbes may produce less hydrogen in order to balance this change. With addition of the BES, total bacteria was not changed. This occurred in the finding of Sparling and Daniels (1987) that BES did not appear to inhibit the bacterial growth.

In summary, BES significantly inhibited the growth of methanogens, reduced methane production, and influenced the microflora of rumen fluid as well. However, the effect of BES on different orders of methanogens needs further investigation.

\section{REFERENCES}

Demeyer D.I., Van Nevel C.J., 1975. Methanogenesis, an integrated part of carbohydrate fermentation and its control. In: I.W. McDonald, A.C.I. Warner (Editors). Digestion and Metabolism in the Ruminant. University of New England Publishing Unit, Armidale, pp. 366-382

Denman S.E., McSweeney C.S., 2006. Development of a real-time PCR assay for monitoring anaerobic fungal and cellulolytic bacterial populations within the rumen. FEMS Microbiol. Ecol. 58, 572-582

Hu W.L., Liu J.X., Ye J.A., Wu Y.M., Guo Y.Q., 2005. Effect of tea saponins on rumen fermentation in vitro. Anim. Feed Sci. Tech. 120, 333-339

Johnson K.A., Johnson D.E., 1995. Methane emissions from cattle. J. Anim. Sci. 73, 2483-2492

Mauricio R.M., Mould F.L., Dhanoa M.S., Owen E., Channa K.S., Theodorou M.K., 1999. A semiautomated in vitro gas production technique for ruminant feedstuff evaluation. Anim. Feed Sci. Tech. 79, 321-330

Moss A.R., Jouany J., Newbold J., 2000. Methane production by ruminants: its contribution to global warming. Ann. Zootech. 49, 231-253

Sauer F.D., Teather R.M., 1987. Changes in oxidation reduction potentials and volatile fatty acid production by rumen bacteria when methane synthesis is inhibited. J. Dairy Sci. 70, 1835-1840

Sparling R., Daniels L., 1987. The specificity of growth inhibition of methanogenic bacteria by bromoethanesulfonate. Can. J. Microbiol. 33, 1132-1136

Tajima K., Aminov R.I., Nagamine T., Matsui H., Makamura M., Benno Y., 2001. Diet-dependent shifts in the bacterial population of the rumen revealed with real-time PCR. Appl. Environ. Microbiol. 67, 2766-2774 